\title{
Stucchi López Raygada, Pierino, José Bezada Alencastre y Óscar García Tipismana (comps.). Manual de derecho del consumo aplicado a los servicios bancarios. Lima: Palestra, 2021
}

Por Néstor Jiménez Martell y Joseph Orellana Capcha

Estudiantes de la carrera de Derecho Corporativo de la Universidad ESAN

El Manual de derecho del consumo aplicado a los servicios bancarios es una obra moderna y pedagógica sobre el tema de los derechos del consumidor en sus relaciones con el mercado bancario. El lector observará con interés que su objetivo principal es dar a conocer de manera clara y detallada - gracias a la precisión con la que ha sido redactado- la actividad bancaria en su relación con el cliente dentro del sistema financiero, así como la protección que se le debe brindar al consumidor.

En cuanto a la parte formal, el libro consta de un prólogo y cinco capítulos. El autor del prólogo, el profesor José Carlos Purizaca Vega, con una sencilla pero profunda presentación, se refiere a la nítida explicación que se hace en el libro de los fundamentos de la relación entre el consumidor y el consumo bancario. Y los capítulos son los siguientes: I. Fundamentos de las relaciones de consumo en el ámbito bancario; II. La contratación de consumo en el ámbito bancario; III. Derecho a la información; IV. Derecho a la idoneidad; V. Consultas, reclamos, controversias y cumplimiento normativo (compliance).

En el primer capítulo se explican de forma minuciosa y precisa los conceptos necesarios para comprender la importancia que tiene el sistema financiero para un país, puesto que es fundamental entender el funcionamiento de los servicios bancarios desde el punto de vista del consumidor en armonía con lo que dicho sector debe ofrecer al cliente. La exposición se torna para el lector en un entendimiento provechoso y didáctico.

Por otro lado, los autores especifican la importancia que tienen el ahorro, el crédito y la actividad bancaria, presentando a los lectores los componentes y las características de esta última como mercado indirecto. Se explica, además, cómo es que el consumidor asume un rol importante en ese sector, teniendo en cuenta de qué modo se deben entender el ahorro y el crédito, ya que forman parte fundamental del bienestar y el desarrollo de las personas.

Los autores se enfocan en la actividad bancaria y cuáles son las relaciones de consumo, teniendo como partes vinculantes al consumidor y al proveedor. 
El primero utiliza o disfruta como destinatario final el producto o servicio que se le ofrece, mientras que el segundo ofrece de manera habitual el bien o servicio, bajo la mirada reguladora de la Superintendencia de Banca, Seguros y AFP (SBS) y la supervisión del Instituto Nacional de Defensa de la Competencia y de la Protección de la Propiedad Intelectual (Indecopi).

Asimismo, para beneficio del lector, los autores analizan de forma didáctica los consumos digitales en el ámbito bancario y el funcionamiento de los llamados fintech. De esta manera, brindan al lector un conocimiento conciso de los servicios y de las garantías que tiene el consumidor al usarlos, gracias a Internet, así como de los alcances esenciales para el desarrollo en la actividad financiera dentro de las plataformas digitales de los bancos.

En el capítulo dos, algo muy importante y destacable que el lector aprenderá es cómo se contrata el consumo en el ámbito bancario. Para ello, los autores dan a conocer puntos claves acerca de los alcances que tiene la regulación de la contratación dentro del consumo bancario y cómo el Código de Protección del Consumidor - el Código- establece una regulación especial para este tipo de contratos y su desarrollo en una regulación sectorial gracias a las normas emitidas por las SBS.

En relación con este punto, y considerando las normas del Código, los autores detallan las reglas generales aplicables a los contratos bancarios de consumo. Para este tipo de regulación sectorial, el lector podrá encontrar la regulación aplicable a: i) operaciones activas, ii) operaciones pasivas y iii) la que es común a ambas.

Al mismo tiempo, dentro de estas reglas aplicables a la contratación bancaria los autores desarrollan y exponen, para una mayor comprensión del lector, cómo debe entenderse el contenido del contrato de consumo y sobre el ejercicio de los derechos contractuales de la desvinculación en esta materia. Han elaborado cuadros descriptivos y comparativos que permiten al lector tener una mirada sistemática tanto de la doctrina como lo regulado por el Código en estos asuntos.

Además, los autores exponen acerca de las reglas especiales que se aplican a la contratación bancaria de consumo mediante cláusulas no negociadas. El lector podrá conocer sobre los contenidos de un acceso oportuno dentro del contrato y la adecuada comprensión de aquellos, así como la importancia de la buena fe en el equilibrio contractual y la prohibición de las llamadas «cláusulas abusivas». 
Igualmente, el lector tendrá la posibilidad de comprender de manera más sencilla los mecanismos señalados por el Código dentro de la regulación sectorial, como son i) la aprobación administrativa previa de cláusulas generales de contratación, ii) la regulación sobre cláusulas abusivas, iii) la modificación de estipulaciones contractuales y iv) la interpretación proconsumidor. Detallados cuadros previstos y elaborados por los autores contribuyen a una mejor y didáctica comprensión del tema.

En el tercer capítulo, los autores desarrollan de manera concisa lo concerniente al derecho de la información. Para ello guían al lector a través de un hilo lógico entre la libertad de elección y el derecho a la información del consumidor, lo que necesariamente lleva a definir y desarrollar qué es la información relevante, desde las exigencias de la normativa nacional hasta la metodología, para poder identificar cuál es la información relevante que las empresas deben brindar a los consumidores.

Los autores parten de la acertada premisa de que, para hablar de libertad del consumidor en la elección, el lector debe presuponer la existencia de la información relevante. Se desarrolla la idea de que no se pueden abordar adecuadamente los asuntos del ámbito bancario sin esta presuposición, puesto que, al hacerlo, se estaría quitando el sentido al argumento de que la competencia beneficia al consumidor.

En estricto, un consumidor que no puede acceder a información relevante no puede tomar decisiones acertadas que lo beneficien, no importa cuántas opciones de elección tenga. En ese orden de ideas, el lector se verá invitado a reflexionar sobre la importancia de la información relevante en la toma de las decisiones, considerándola información «veraz, suficiente, de fácil comprensión, apropiada, oportuna y accesible» que le permite «valorar y comparar» las ofertas del mercado bancario.

Asimismo, los autores desarrollan lo que la normativa exige a cada entidad bancaria en el momento en que se ofrece la información relevante al consumidor. Son tres las exigencias que esto implica: i) que la información sea veraz, ii) que la información relevante sea ofrecida de manera oportuna (tanto antes como después de la contratación) y iii) que la información relevante se ofrezca apropiadamente. El lector, por tanto, no solo encontrará una gran precisión en el desarrollo de cada una de las cuestiones, sino que dispondrá, además, del paralelismo que existe entre el derecho del consumidor a la información relevante y la obligación de los proveedores bancarios a ofrecerlos. 
Los autores incluyen en el mismo capítulo una serie de descripciones en las que se detalla qué información se considera relevante para la normativa peruana, desde la garantía constitucional hasta las normas con rango de ley y las normas reglamentarias. Sin duda, a pesar de no extenderse tanto en este aspecto, los autores logran ofrecer al lector mucho más que un esbozo del derecho bancario y de protección al consumidor, pues se trata de información relevante sobre el tema.

El capítulo cierra con una serie de reflexiones y consideraciones sobre la información relevante y su relación con el principio de transparencia, que es sistemático en todo el Código de Protección al Consumidor.

Una vez que los autores han desarrollado con eficacia el derecho a la información, invitan al lector a adentrarse en el análisis del derecho a la idoneidad o, dicho de otra manera, que el consumidor, al acceder a los productos y servicios bancarios, se encuentre con que estos sean idóneos.

Asimismo, el lector hallará que el derecho a la idoneidad también está íntimamente ligado a la libertad de elección y a su accesibilidad a la información, lo que nos invita a apreciar una vez más el esfuerzo que los autores realizan para guiarnos a una lectura con una secuencia lógica y apreciar el vínculo sistemático que tiene el derecho.

Los autores no solo brindan un concepto detallado de lo que significa producto o servicio bancario idóneo, sino que también desarrollan la vinculación que exige el Código entre la idoneidad y la libre elección del consumidor, siendo que la defensa de esta relación solo es posible mediante las garantías.

El desarrollo de las garantías desempeña un papel principal en el cuarto capítulo, y es muy interesante observar cómo los autores exponen cada uno de los tipos de garantía regulados en el Perú: i) las garantías legales, ii) las garantías explícitas y iii) las garantías implícitas.

El capítulo concluye con una serie de aspectos que están vinculados con el derecho a la idoneidad, tales como las órdenes de pago en el escenario de las tarjetas de crédito o la obligación de ofrecer y garantizar la seguridad de estas, así como los métodos comerciales abusivos, entre otros. Sin duda, el lector se sentirá satisfecho con cada uno de los ejemplos detallados, la manera de presentarlos — con facilidad, claridad y actualidad-, puesto que los autores incluyen en sus análisis lo más reciente que se ha tratado en cuanto a la doctrina y la regulación bancaria nacional.

El último capítulo del manual se ocupa de todo lo relacionado con las consultas, reclamos, controversias e incluso de la necesidad del compliance en 
las instituciones bancarias. En palabras mismas de los autores, «se presentan las vías generales que tienen a su disposición los consumidores [...], así como la importancia de los programas de cumplimiento normativo».

Los autores desarrollan para el lector los mandatos que tienen las instituciones públicas como el Indecopi o la SBS para que el mercado bancario no pierda la esencia constitucional de «economía social de mercado» para el beneficio mutuo, tanto de la institución financiera como del cliente del producto o servicio bancario. Detallan con precisión lo que persiguen ambas instituciones, tanto en conjunto como por separado, para el desarrollo nacional y la protección del consumidor.

En este último capítulo los autores dan a conocer al lector, de forma ordenada y puntual, cómo son los mecanismos autocompositivos para la solución de controversias. Del mismo modo, de qué manera el consumidor puede lograr una atención directa a sus reclamos haciendo uso de la conciliación, la mediación y, sobre todo, de la defensa dentro del interés colectivo.

En segundo lugar, los autores exponen también el mecanismo heterocompositivo dentro de la solución de controversias, al mostrarnos los procedimientos que el consumidor tiene a su disposición para resolver las controversias ante un banco. Para ello, se presentan al lector en forma sintetizada los procedimientos que se necesitan realizar ante la Defensoría del Cliente Financiero (DCF) y precisan cuáles no se encuentran dentro del ámbito de protección al consumidor.

Igualmente, los autores señalan los procedimientos que se presentan ante el Indecopi, tales como el i) el procedimiento sumarísimo y ii) el procedimiento ordinario. Para esto, el lector conocerá cómo el consumidor puede optar por un proceso judicial, sin perjuicio de las otras vías disponibles anteriormente presentadas para la solución de controversias.

El capítulo finaliza analizando la importancia de los programas de cumplimiento normativo (compliance), que, en materia de protección al consumidor y publicidad comercial, tienen como finalidad dar a conocer al lector de forma clara y precisa su funcionamiento.

En suma, este manual contiene una vasta información acerca de la protección y la regulación en el ámbito bancario de consumo. La ofrece en un lenguaje sencillo no solo para los que se desenvuelven en el mundo del derecho, sino también para el público en general, puesto que todos somos consumidores de los productos y servicios bancarios. 